\title{
A decade of improvement: New York State fluid milk quality
}

\author{
N. H. Martin, N. R. Carey, S. C. Murphy, M. Wiedmann, and K. J. Boor ${ }^{1}$ \\ Milk Quality Improvement Program, Department of Food Science, Cornell University, Ithaca, NY 14853
}

\begin{abstract}
The microbiological and sensory qualities of New York State (NYS) fluid milk products were assessed as part of an ongoing fluid milk quality program. Commercially packaged pasteurized fluid milk samples were collected twice a year over the 10-yr period from 2001 to 2010 from 14 NYS dairy processing facilities and analyzed at the Milk Quality Improvement Program (MQIP) laboratory. Each sample was tested throughout refrigerated storage $\left(6^{\circ} \mathrm{C}\right)$ on day initial, 7,10 , and 14 for standard plate count (SPC), coliform count (CC), and sensory quality. Over the 10-yr period, the percentage of samples with bacterial numbers below the Pasteurized Milk Ordinance (PMO) limit of 20,000 cfu/ $\mathrm{mL}$ at $\mathrm{d} 14$ postprocessing ranged from a low of $21.1 \%$ in 2002 to a high of $48.6 \%$ in 2010. Percent samples positive for coliforms during that same period ranged from a high of $26.6 \%$ in 2002 to a low of $7.5 \%$ in 2007 . Mean d 14 sensory scores ranged from a low of 6.0 in 2002 to a high of 7.3 in 2007. Samples contaminated with coliforms after pasteurization have significantly higher SPC counts and significantly lower sensory scores on d 14 of shelf-life than those not contaminated with coliforms. Product factors such as fat level were not significantly associated with SPC, CC, or sensory quality of the product, whereas the factor processing plant significantly affected overall product quality. This study demonstrates that overall fluid milk quality in NYS, as determined by microbiological and sensory analyses, has improved over the last decade, and identifies some challenges that remain.
\end{abstract}

Key words: fluid milk, shelf life, milk quality

\section{INTRODUCTION}

As the US dairy industry faces changing markets, declining consumption levels on an individual consumer basis, and longer distribution times, the need for higher quality, longer shelf-life product has become paramount. Pasteurized fluid milk quality is evaluated

Received May 24, 2012.

Accepted August 30, 2012.

${ }^{1}$ Corresponding author: kjb4@cornell.edu by microbiological standards as well as sensory perception, 2 parameters that are closely associated (Fromm and Boor, 2004; Carey et al., 2005). The Pasteurized Milk Ordinance (PMO; FDA, 2011) specifies limits for total bacterial counts and coliforms of 20,000 cfu/ $\mathrm{mL}$ and $10 \mathrm{cfu} / \mathrm{mL}$, respectively, throughout product shelf life in Grade A pasteurized fluid milk. Although no regulatory standards exist for the sensory quality of fluid milk, consumers reject poor quality products (Bodyfelt et al., 1988).

Challenges to improving fluid milk quality and extending shelf life are many. Historically, the greatest challenge has been controlling and eliminating postpasteurization contamination (PPC), and PPC with gram-negative psychrotolerant organisms such as Pseudomonas results in fluid product spoilage in as little as $7 \mathrm{~d}$ postprocessing (Ranieri and Boor, 2009). The growth of Pseudomonas and other PPC organisms in fluid milk can result in undesirable changes in flavor, odor, and appearance (Dogan and Boor, 2003; Sperber and Doyle, 2009), which is detrimental to consumer sensory acceptance. With comprehensive cleaning and sanitation programs in place, processors can virtually eliminate PPC, which can extend product shelf life, defined as the amount of time required for the total bacterial count of the sample to reach $20,000 \mathrm{cfu} /$ $\mathrm{mL}$, to $17 \mathrm{~d}$ and beyond. The microorganisms most often responsible for fluid milk spoilage when PPC is eliminated include strains of the psychrotolerant, gram-positive, spore-forming rods Paenibacillus and Bacillus (Fromm and Boor, 2004; Durak at al., 2006; Huck et al., 2007; Ranieri et al., 2009), which typically reach spoilage levels under refrigeration within 17 to $21 \mathrm{~d}$ after pasteurization. These organisms can enter the milk supply at various points in the milk-handling continuum and survive pasteurization in spore form. Subsequently, certain subtypes can grow to spoilage levels at refrigeration temperature.

Plant-specific factors other than PPC also influence fluid milk quality. For example, an inverse relationship exists between conventionally applied ranges of HTST pasteurization temperatures and bacterial outgrowth in fluid milk (Ranieri et al., 2009; Martin et al., 2012). Process optimization, consistent application of good manufacturing practices, and control of the cold chain 
from harvest through processing and distribution are critical in producing high-quality fluid milk products. This study assesses the quality of New York State (NYS) fluid milk from 2001 to 2010.

\section{MATERIALS AND METHODS}

\section{Sample Collection and Handling}

Samples were collected by Milk Quality Improvement Program (MQIP; Cornell University, Ithaca, NY) personnel at 14 NYS fluid milk processing facilities during semiannual visits from 2001 to 2010 . The processing capacity of the plants participating in this study ranged in size from $<1$ million to $>600$ million lbs. Due to the involvement of select NYS processors in another MQIP research project, visits were announced from 2007 through 2010. Packaged pasteurized products collected represented the products processed at each facility, including whole fat (3.25\% milk fat minimum), reduced fat $(1.5 \%$ or $2 \%$ milk fat), lowfat ( $1 \%$ milk fat), and nonfat $(<0.2 \%$ milk fat $)$ milk in quart $(946 \mathrm{~mL})$, half gallon $(1.9 \mathrm{~L})$, or gallon $(3.8 \mathrm{~L})$ containers. Packaging containers included glass bottles, high-density polyethylene jugs, or paperboard cartons. Milk samples were transported to the MQIP laboratory in coolers packed with ice or ice packs. Samples were held at or below $4^{\circ} \mathrm{C}$, without freezing, until the initial testing, which occurred within 24 to $48 \mathrm{~h}$ of sample collection.

Samples were tested for microbiological and sensory quality on the initial day (defined as the first day of testing, which varied in day of shelf-life from d 0 to 6 , depending on processing schedule) and on $\mathrm{d} 7,10$, and 14 postprocessing. Products from a subset of processors with histories of manufacturing high-quality products were also tested at d 17 postprocessing. Upon arrival in the laboratory, containers were completely inverted 25 times, and then samples were aseptically distributed among 4 or 5 sterile $500-\mathrm{mL}$ glass bottles $(\sim 400 \mathrm{~mL} /$ bottle) in anticipation of the planned number of product testing days for a given plant's samples. Bottles were stored at $6^{\circ} \mathrm{C}$ for the remainder of shelf-life testing.

\section{Shelf-Life Analysis}

Microbiological analyses on each test day were conducted in accordance with Standard Methods for the Examination of Dairy Products (Laird et al., 2004) and included total aerobic plate count on SPC medium (Difco, BD Diagnostics, Franklin Lakes, NJ; pour plated from 2001 to 2006; spiral plated from 2007 to 2010) followed by incubation at $32^{\circ} \mathrm{C}$ for $48 \mathrm{~h}$, and coliform count by pour plating on violet red bile agar (Difco; from 2001 to 2006) or according to the manufacturer's instructions on Petrifilm Coliform Count plates (3M, St. Paul, MN; from 2007 to 2010), both incubated at $32^{\circ} \mathrm{C}$ for $24 \mathrm{~h}$. Presumptive coliform colonies detected on violet red bile agar pour plates were confirmed using brilliant green bile broth (Difco).

Milk samples were evaluated for sensory quality on the initial day and on $\mathrm{d} 7,10$, and 14 postprocessing in accordance with the guidelines of the American Dairy Science Association, as described previously (Bodyfelt et al., 1988). Products from a subset of processors with histories of manufacturing high-quality products were also tested at d 17 postprocessing. Sensory samples were mixed by inverting the sample bottle 25 times according to Laird et al. (2004). Under dim lighting conditions (to minimize light oxidation), approximately 50-mL aliquots were poured into sample cups labeled with random 3-digit identification codes. Samples were held at $6^{\circ} \mathrm{C}$ until testing, at which time the samples were warmed to approximately $15^{\circ} \mathrm{C}$ using a microwave for a predetermined amount of time. Flavor criticisms (using predefined sensory attributes) and individual flavor scores for a given product were assigned by each member of a trained panel of 6 staff and students from Cornell University (Ithaca, NY). Sensory scores of 9.0 and 10.0 were considered "excellent," scores of 8.0 to 8.9 were considered "good," scores of 6.1 to 7.9 were considered "fair," and scores of 6.0 and below were considered "unacceptable." An average overall flavor quality score for each sample on each testing day was computed from the individual scores using the Compusense 5 (v4.6, Compusense Inc., Guelph, ON, Canada) computerized data collection program. This study was granted exempt status from human subject approval by the Cornell University Committee on Human Subjects.

\section{Statistical Analysis}

All statistical analyses were performed in JMP (version 7.0, SAS Institute Inc., Cary, NC). Microbiological data were log-transformed before linear and logistic regression analyses, Pearson $\chi^{2}$, Tukey-Kramer honestly significant difference test, and ANOVA.

\section{RESULTS AND DISCUSSION}

During the 10-yr period (2001 to 2010), 1,008 commercially packaged fluid milk samples were collected from 14 NYS dairy processing facilities. Of the 1,008 samples collected, 277 were whole fat $(3.25 \%$ fat or greater), 252 were reduced fat $(1.5 \%$ or $2 \%$ fat $), 203$ were low fat $(1 \%)$, and 276 were nonfat $(<0.2 \%$ milk fat). 


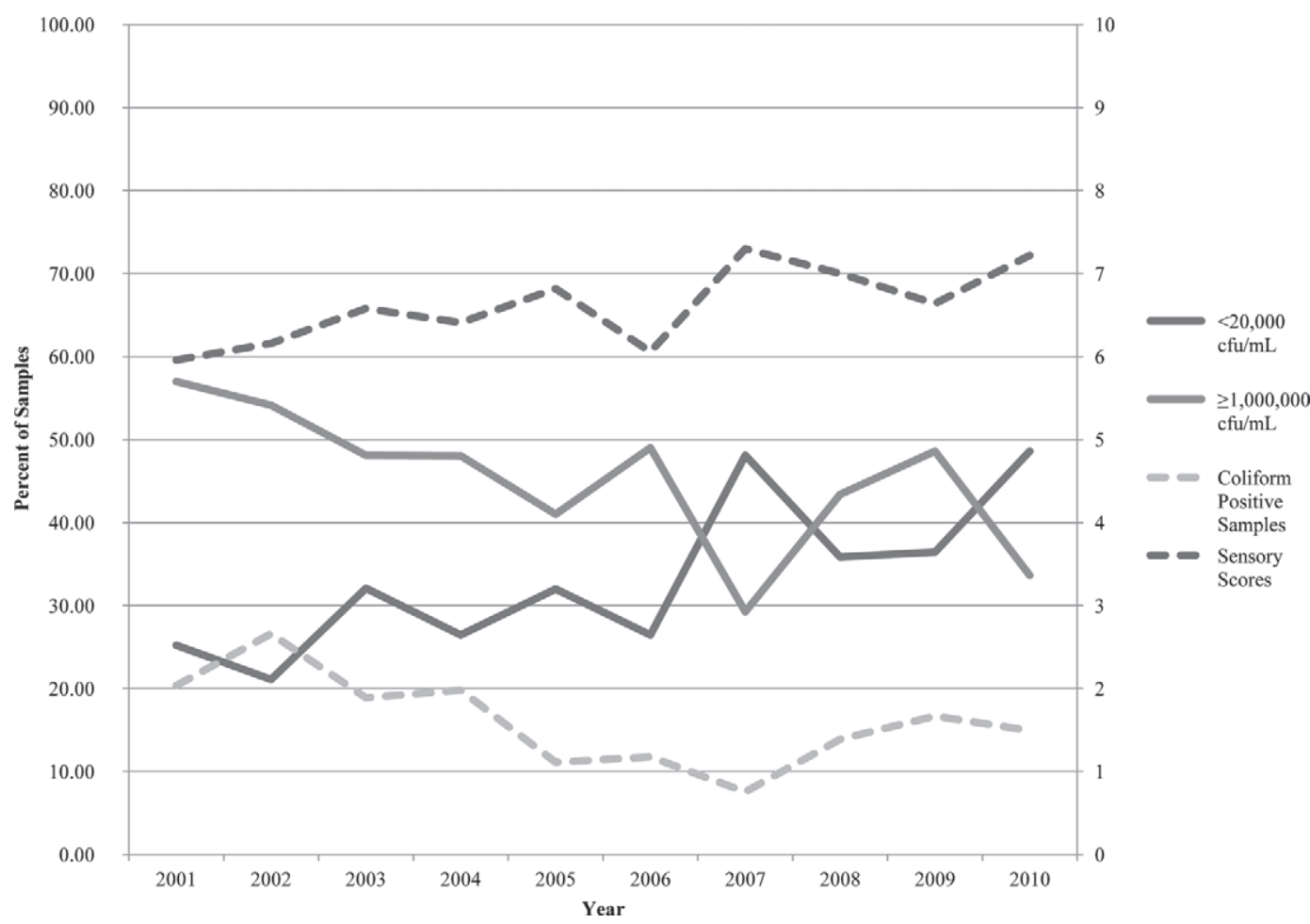

Figure 1. Fluid milk quality parameters for samples collected from 14 New York State milk processors between 2001 and 2010 , showing percentage of d 14 samples $<20,000 \mathrm{cfu} / \mathrm{mL}$ (solid dark-gray line); percentage of d 14 samples $>1,000,000 \mathrm{cfu} / \mathrm{mL}$ (solid light-gray line); percentage of samples positive for coliforms (all days of shelf life; dashed light-gray line); and mean d 14 sensory score (dashed dark-gray line).

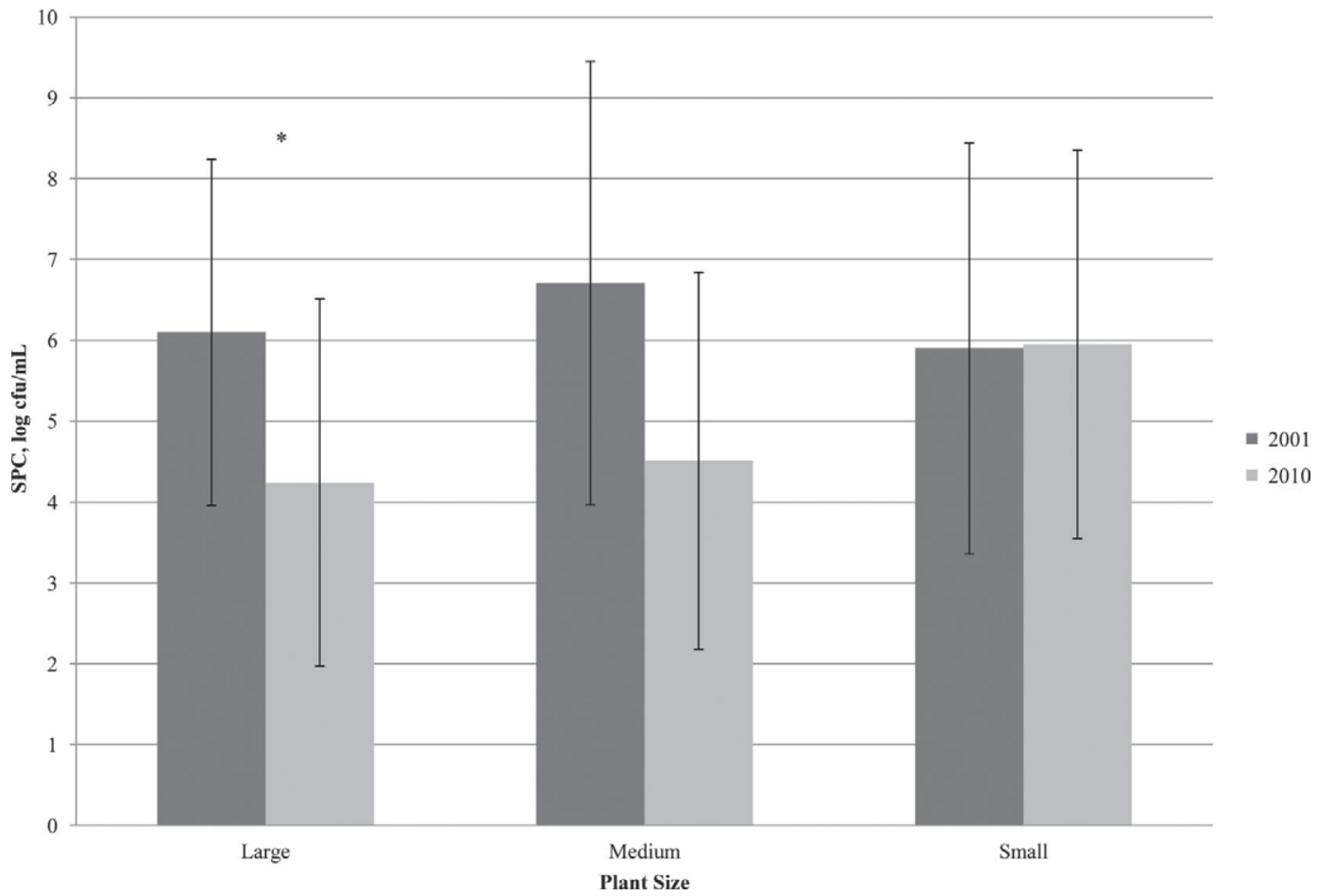

Figure 2. Total mean SPC (log cfu/mL) at d 14 postpasteurization of refrigerated storage for large (processing $\geq 100,000,000$ lbs of milk per year), medium (processing $\geq 10,000,000$ but $<100,000,000 \mathrm{lbs}$ of milk per year), and small (processing $<10,000,000$ lbs of milk per year) New York State processors. Bars represent $\pm 1 \mathrm{SD} ;{ }^{*}$ indicates a significant difference $(P<0.05)$ in bacterial numbers between years. 


\section{NYS Fluid Milk Quality Improved Between 2001 and 2010}

Results of analyses indicated an overall improvement in NYS commercial fluid milk quality between 2001 and 2010. The percentage of d 14 samples with bacterial counts less than or equal to the PMO limit of 20,000 $\mathrm{cfu} / \mathrm{mL}$ (FDA, 2011) ranged from a low of $21.1 \%$ in 2002 to a high of $48.6 \%$ in 2010 (Figure 1). The percentage of samples with bacterial counts $>1,000,000 \mathrm{cfu} / \mathrm{mL}$, a level conventionally considered to be associated with a high likelihood of detection of noticeable off-flavors by untrained consumers (Carey et al., 2005), ranged from a high of $57.0 \%$ in 2001 to a low of $29.2 \%$ in 2007 (Figure 1). The percentage of samples with total bacterial counts $>1,000,000 \mathrm{cfu} / \mathrm{mL}$ trended downward from 2001 to 2007 and then rose again in 2008 and 2009. The reason for these increases in bacterial numbers is not known. Samples positive for coliforms (at any day of shelf life) ranged from a high of $26.6 \%$ in 2002 to a low of $7.6 \%$ in 2007 (Figure 1). Mean d 14 sensory scores over the 10-yr period ranged from a low of 5.9 in 2001 to a high of 7.2 in 2010 (Figure 1), whereas mean d 17 scores for the subset of plants that had historically produced high-quality products ranged from a low of 7.28 in 2001 to a high of 8.21 in 2010.

Significant improvements in d $14 \mathrm{SPC}(P=0.0004)$ were made by large processors (processing $\geq 100,000,000$ lbs of milk per year) between 2001 and 2010 (Figure 2). Plants in the large-processor group represented $91.3 \%$ of the total volume of milk processed in NYS in 2010. Day 14 SPC did not differ significantly in 2001 and 2010 for plants of medium size (processing $\geq 10,000,000$ but $<100,000,000 \mathrm{lbs}$ of milk per year) or of small size (processing $<10,000,000$ lbs of milk per year, $P=$ 0.0675 and $P=1.0000$, respectively; Figure 2). Plants in the medium-processor group represented $8.5 \%$ of the milk processed in NYS in 2010, whereas plants in the small-processor group represented approximately $0.2 \%$ of the milk processed in NYS in 2010.

To evaluate individual plant trends over time, each plant was categorized by performance, as having (1) consistently good quality, (2) an improvement in quality, or (3) consistent quality challenges from 2001 to 2010 (Figure 3). Plants categorized as having consistently good quality $(\mathrm{n}=3)$ were characterized by yearly mean d $14 \mathrm{SPC}$ that remained below $10^{6} \mathrm{cfu} /$ $\mathrm{mL}$, yearly mean $\mathrm{d} 14$ sensory scores that remained above 7.0, and infrequent, sporadic coliform contamination. Plants that made improvements in quality $(\mathrm{n}=4)$ over the 10-yr period were characterized by decreasing d 14 SPC counts, increasing d 14 sensory scores, and decreasing percentage of samples with coliform contamination. Finally, plants categorized as having con-
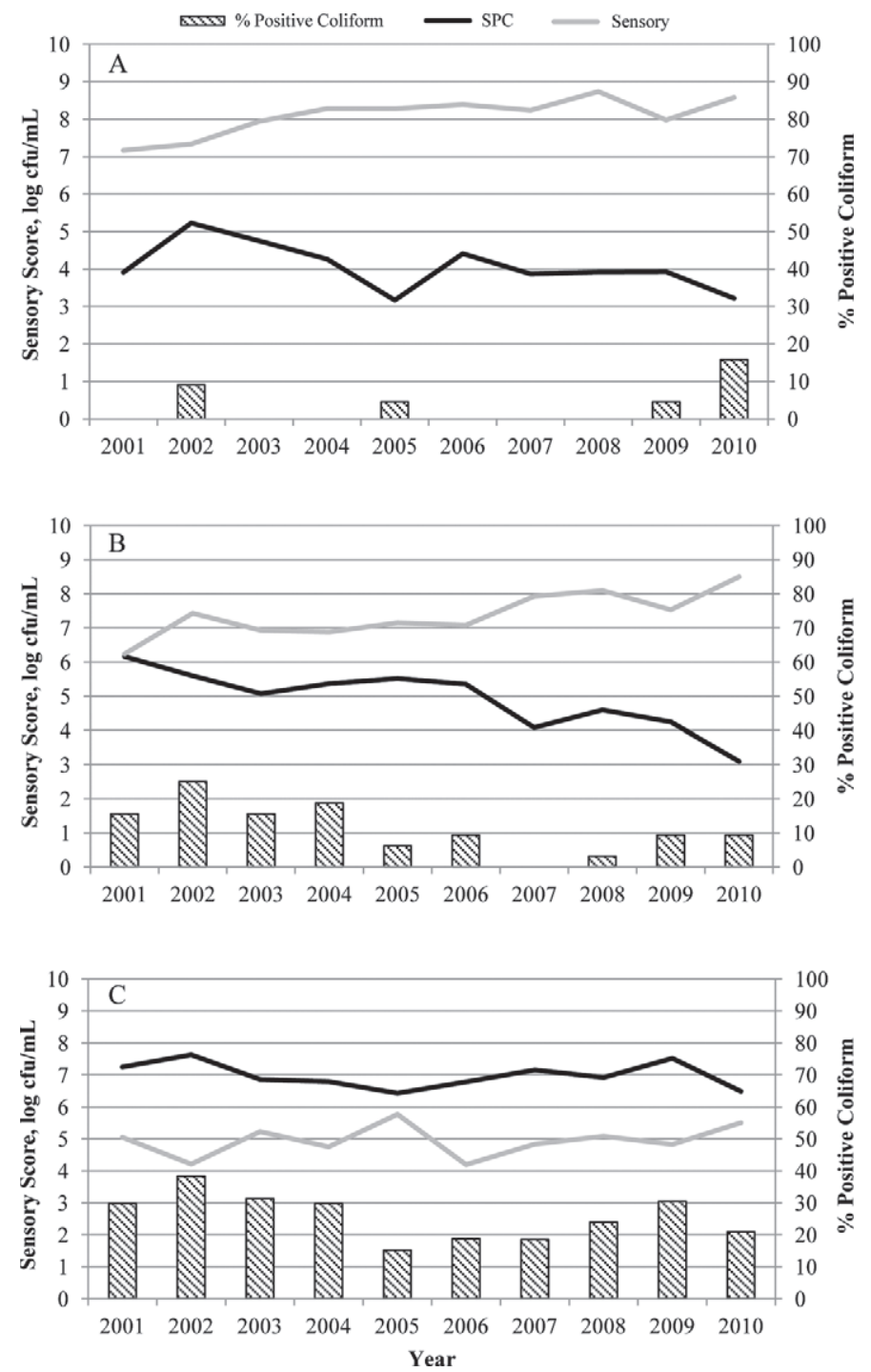

Figure 3. Fluid milk quality parameters, including mean d 14 log total aerobic SPC, percentage of samples positive for coliforms (all days of shelf-life), and mean d 14 sensory scores for samples collected from 14 New York State milk processors over the period from 2001 to 2010 by plant performance, defined as consistently good quality ( $\mathrm{n}=$ 3 ; panel A), improvement in quality $(\mathrm{n}=4$; panel $\mathrm{B})$, or consistent quality challenges $(\mathrm{n}=7$; panel $\mathrm{C})$.

sistent quality challenges $(\mathrm{n}=7)$ over the 10 -yr period were characterized by yearly mean d 14 counts that remained above $10^{6} \mathrm{cfu} / \mathrm{mL}$, yearly mean d 14 sensory scores that remained below 6.0, and a consistently high percentage of products with coliform contamination.

Previous MQIP research (Carey et al., 2005) studied trends in NYS fluid milk quality from 23 processors during the period from 1991 to 2000. Pasteurized milk quality also improved during that period. Compared with the period from 2001 to 2010, results from 1991 to 2000 showed that the percentage of d 14 SPC less 
than $20,000 \mathrm{cfu} / \mathrm{mL}$ ranged from $12 \%$ (1993) to $32 \%$ (2000); the percentage of d $14 \mathrm{SPC}>1,000,000 \mathrm{cfu} /$ $\mathrm{mL}$ ranged from $70 \%$ (1993) to $53 \%$ (2000); and the coliform-positive samples ranged from $34 \%$ (1992) to 21\% (1997 and 2000; Carey et al., 2005). The current results and those of the previous research (Carey et al., 2005) indicate that NYS commercial fluid milk has improved from 1991 to 2010.

\section{Fluid Milk Quality Parameters Are Closely Related}

Our results indicate that, in general, as bacterial counts increase, sensory scores decrease. Importantly, we found that the microbiological quality of milk at $7 \mathrm{~d}$ postprocessing significantly predicts d 14 sensory score (Figure 4). Samples with $\leq 1,000 \mathrm{cfu} / \mathrm{mL}$ (d 7 SPC category $\mathrm{I} ; \mathrm{n}=551$ ) at $7 \mathrm{~d}$ postprocessing had significantly higher $(P<0.0001)$ d 14 sensory scores (mean of 8.1) than samples in $d 7$ SPC category II $(>1,000$ but $\leq 20,000 \mathrm{cfu} / \mathrm{mL} ; \mathrm{n}=188)$, category III $(>20,000$ but $\leq 1,000,000 \mathrm{cfu} / \mathrm{mL} ; \mathrm{n}=181)$, and category IV (>1,000,000 cfu/mL; $\mathrm{n}=81$; Figure 4). Similarly, samples in d 7 SPC category II had significantly higher $(P<0.0001)$ d 14 sensory scores (mean of 5.8) than samples in d 7 SPC categories III and IV (Figure
4). Finally, samples in d 7 SPC category III had significantly higher $(P<0.0001)$ d 14 sensory scores (mean of 3.7) than samples in d 7 SPC category IV (mean 1.5; Figure 4).

The presence of bacterial numbers $\geq 1,000,000 \mathrm{cfu} /$ $\mathrm{mL}$ has been associated with sensory defects detectable by consumers (Carey et al., 2005). Although bacterial numbers and sensory scores are not perfectly correlated, in general, samples with high bacterial numbers tend to have low sensory scores. The sensory defects present in the product generally reflect the quantity and metabolic patterns of the spoilage organisms present (Dogan and Boor, 2003). Although both gram-negative and gram-positive organisms can have detrimental effects on the sensory quality of fluid milk, strain-to-strain variation in sensory spoilage potential is vast (Hayes et al., 2002). Organisms such as Pseudomonas, found frequently in products with $\mathrm{PPC}$, can produce off-odors including fruity and rotten (Hayes et al., 2002). Grampositive spore-formers have previously been described as producing defects such as sweet curdling (Hanson et al., 2005).

The presence of coliforms in pasteurized milk is an indicator of PPC. Samples testing positive for these organisms on the initial day of shelf life had significantly

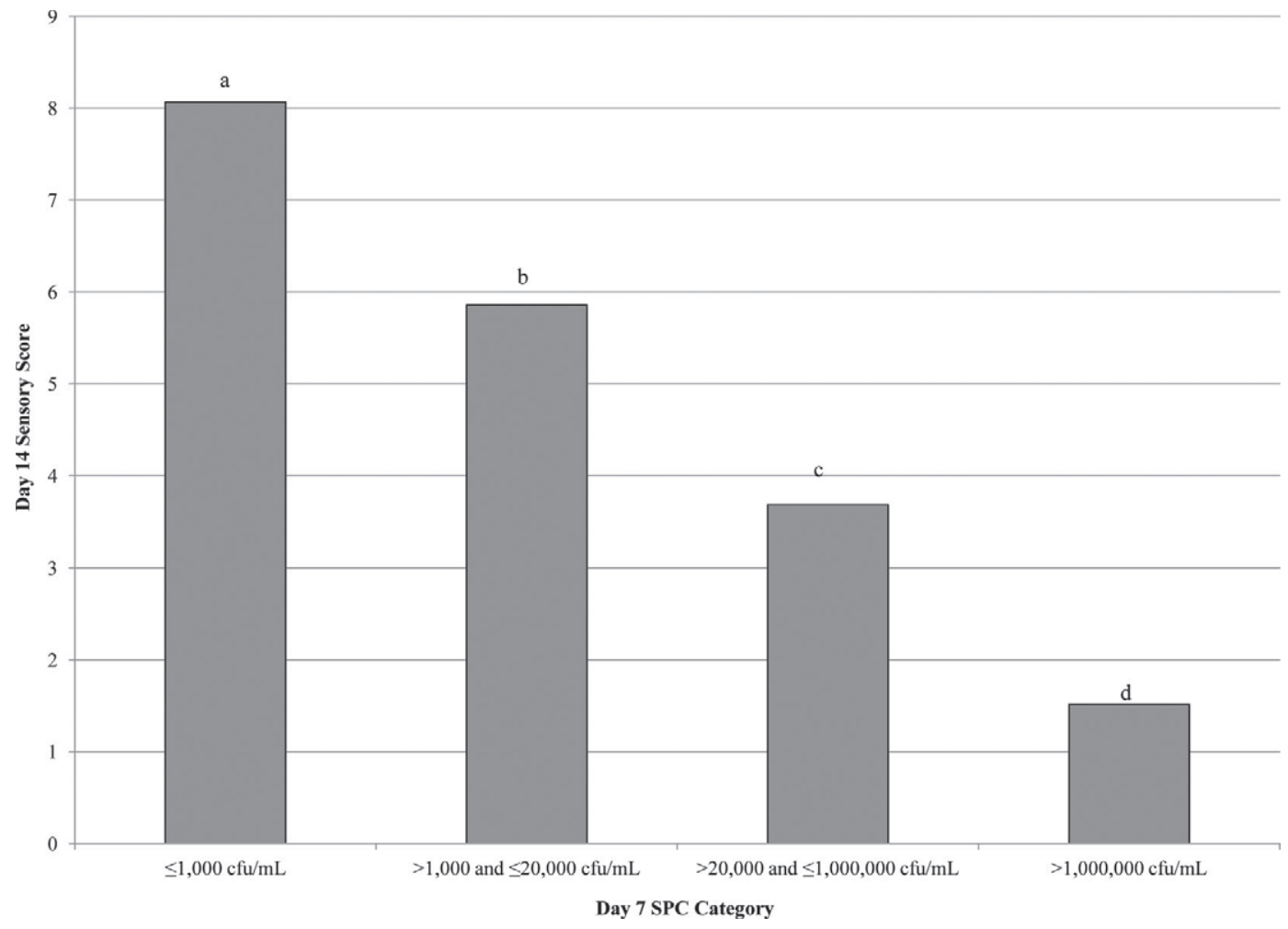

Figure 4. Comparison of d 7 total aerobic SPC categories, where categories are defined as $\leq 1,000 \mathrm{cfu} / \mathrm{mL},>1,000 \mathrm{but} \leq 20,000 \mathrm{cfu} / \mathrm{mL}$, $>20,000$ but $\leq 1,000,000 \mathrm{cfu} / \mathrm{mL}$, and $>1,000,000 \mathrm{cfu} / \mathrm{mL}$, and mean d 14 sensory score. Different letters represent significant differences $(P<$ $0.05)$ in sensory scores. 


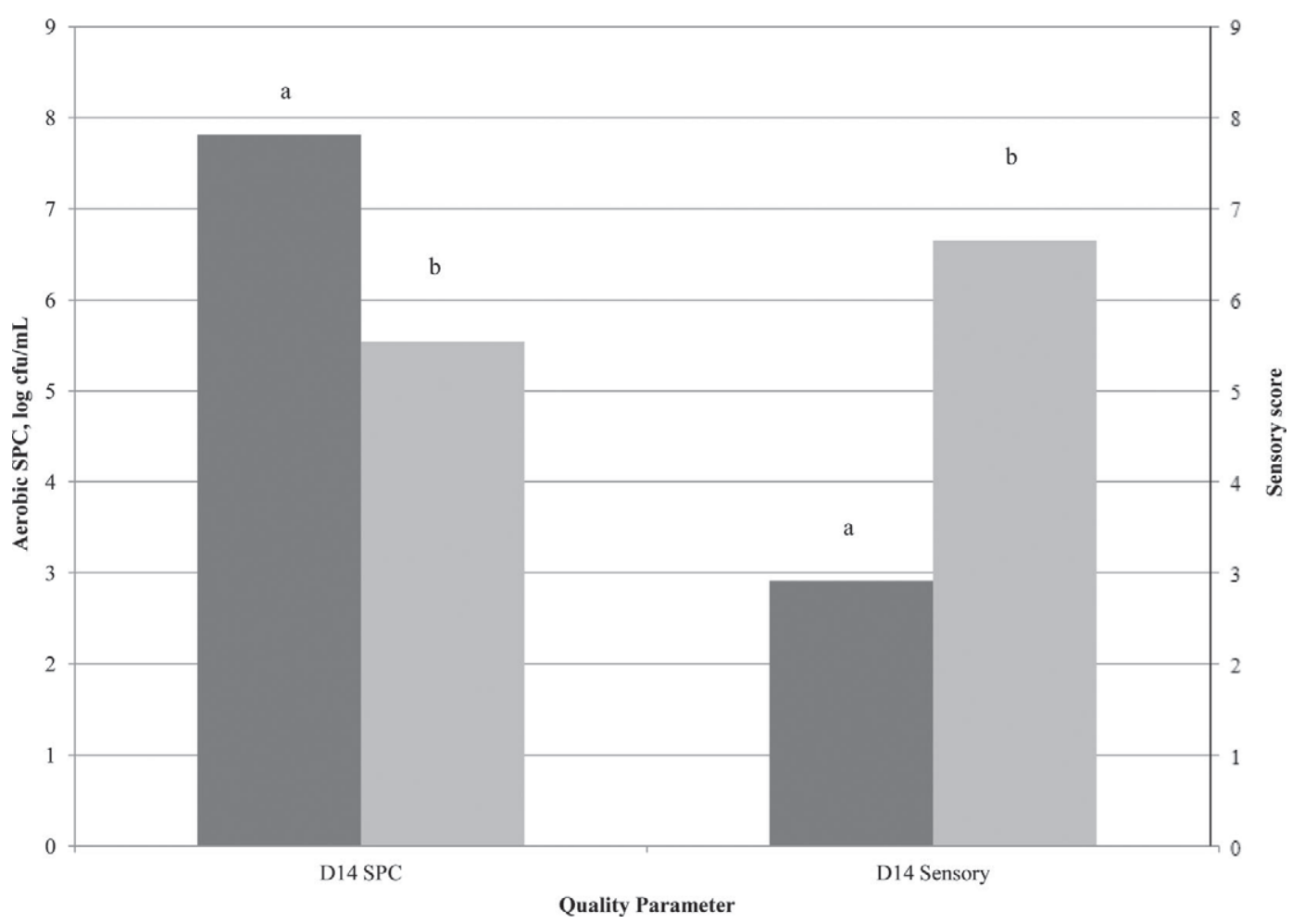

Figure 5. Comparison of pasteurized fluid milk quality parameters, d 14 mean log total aerobic SPC and D14 mean sensory score, for samples positive (dark gray bars) and negative (light gray bars) for coliforms on the initial day of shelf life. Different letters represent significant differences $(P<0.05)$ between means within each quality parameter.

higher $(P<0.0001)$ d 14 SPC and significantly lower $(P$ $<0.0001) \mathrm{d} 14$ sensory scores compared with samples that were not positive for coliforms on the initial day of shelf life (Figure 5). One hundred eleven samples with $>10 \mathrm{cfu} / \mathrm{mL}$ coliforms were not tasted by the sensory panel and, therefore, had no d 14 sensory scores and were not included in this analysis. Our results indicate that the microbiological quality of fluid milk affects sensory quality and, specifically, that the presence of $\mathrm{PPC}$ in the form of coliforms is linked to products with significantly lower sensory quality than when PPC is prevented. Controlling PPC remains an ongoing challenge for some dairy processing plants (Ranieri and Boor, 2009; Martin et al., 2011), despite advances in technology and processing improvements. Controlling PPC is particularly problematic when financial and personnel resources are constrained.

\section{Plant Has a Significant Effect on Fluid Milk Quality}

We evaluated statistically the effects of fat level and plant on fluid milk sensory and microbiological data. Fat level was not a significant factor in d 14 sensory score $(P>0.10)$, d 14 SPC count $(P>0.20)$, or the presence of coliforms $(P>0.10)$. Plant was a significant factor in d 14 sensory score $(P<0.0001)$, d 14 SPC count $(P<0.0001)$, and the presence of coliforms $(P$ $<0.0001)$. Plant-specific factors such as process parameters (i.e., pasteurization time and temperature), cleaning and sanitation programs, and even personnel training can influence finished product quality (Douglas et al., 2000; Martin et al., 2011). Our results reinforce the importance of in-plant contributions to fluid milk quality, emphasizing the attention that these issues should be given in development of a plant's product quality improvement regimen.

\section{CONCLUSIONS}

Improvement of fluid milk quality is an important goal for dairy processors. Although challenges such as PPC persist for some processors, they can be overcome, resulting in higher quality products for consumers. As the beverage industry has become increasingly competitive and consumers are choosing to drink less milk, dairy processors must take action to improve their product quality. Our study indicates that many NYS dairy processors have made improvements in quality or are able to consistently produce high-quality products. Further improvements should focus on eliminating 
PPC, establishing and strictly following cleaning and sanitation programs, and controlling processing parameters to reduce outgrowth of spore-forming bacteria.

\section{ACKNOWLEDGMENTS}

This project was supported by the New York State Milk Promotion Advisory Board through the New York State Department of Agriculture and Markets (Albany, NY) - New York State dairy farmers committed to production of high quality dairy products. The authors thank the technical staff of the Milk Quality Improvement Program (Ithaca, NY).

\section{REFERENCES}

Bodyfelt, F. W., J. Tobias, and G. M. Trout. 1988. The Sensory Evaluation of Dairy Products. Van Nostrand Reinhold, New York, NY.

Carey, N. R., S. C. Murphy, R. N. Zadoks, and K. J. Boor. 2005. Shelf lives of pasteurized fluid milk products in New York State: A tenyear study. Food Prot. Trends. 25:102-113.

Dogan, B., and K. J. Boor. 2003. Genetic diversity and spoilage potentials among Pseudomonas spp. isolated from fluid milk products and dairy processing plants. Appl. Environ. Microbiol. 69:130138

Douglas, S. A., M. J. Gray, A. Crandall, and K. J. Boor. 2000. Characterization of chocolate milk spoilage patterns. J. Food Prot. 63:516-521.

Durak, M. Z., H. I. Fromm, J. R. Huck, R. N. Zadoks, and K. J. Boor. 2006. Development of molecular typing methods for Bacillus spp. and Paenibacillus spp. isolated from fluid milk products. J. Food Sci. 71:M50-M56.

FDA. 2011. Standards for grade "A" milk and milk products. Pages 28-31 in Grade "A" Pasteurized Milk Ordinance. Standards for grade "A" milk and milk products. US Department of Health and Human Services, Public Health Service, Washington, DC.

Fromm, H. I., and K. J. Boor. 2004. Characterization of pasteurized fluid milk shelf-life attributes. J. Food Sci. 69:207-214.

Hanson, M. L., W. L. Wendorff, and K. B. Houck. 2005. Effect of heat treatment of milk on activation of Bacillus spores. J. Food Prot. 68:1484-1486.

Hayes, W., C. H. White, and M. A. Drake. 2002. Sensory aroma characteristics of milk spoilage by Pseudomonas species. J. Food Sci $67: 448-454$

Huck, J. R., N. H. Woodcock, R. D. Ralyea, and K. J. Boor. 2007. Molecular subtyping and characterization of psychrotolerant endospore-forming bacteria in two New York State fluid milk processing systems. J. Food Prot. 70:2354-2364.

Laird, D. T., A. Gambrel-Lenarz, F. M. Scher, T. E. Graham, and R. Reddy. 2004. Microbiological count methods. Pages 153-186 in Standard Methods for the Examination of Dairy Products. 17th ed. H. M. Wehr and J. F. Frank, ed. Am. Public Health Assoc., Washington, DC.

Martin, N. H., M. L. Ranieri, S. C. Murphy, R. D. Ralyea, M. Wiedmann, and K. J. Boor. 2011. Results from raw milk microbiological tests do not predict the shelf-life performance of commercially pasteurized fluid milk. J. Dairy Sci. 94:1211-1222.

Martin, N. H., M. L. Ranieri, M. Wiedmann, and K. J. Boor. 2012. Reduction of pasteurization temperature leads to lower bacterial outgrowth in pasteurized fluid milk during refrigerated storage: a case study. J. Dairy Sci. 95:471-475.

Ranieri, M. L., and K. J. Boor. 2009. Short communication: Bacterial ecology of high-temperature, short-time pasteurized milk processed in the United States. J. Dairy Sci. 92:4833-4840.

Ranieri, M. L., J. R. Huck, M. Sonnen, D. M. Barbano, and K. J. Boor. 2009. High temperature, short time pasteurization temperatures inversely affect bacterial numbers during refrigerated storage of pasteurized fluid milk. J. Dairy Sci. 92:4823-4832.

Sperber, W. H., and M. P. Doyle, ed. 2009. Compendium of the Microbiological Spoilage of Foods and Beverages. Springer Science + Business Media LLC, New York, NY. 